\title{
EGFR NP_005219.2:p.L858K
}

National Cancer Institute

\section{Source}

National Cancer Institute. EGFR NP 005219.2:p.L858K. NCI Thesaurus. Code C98507.

A change in the amino acid residue at position 858 in the epidermal growth factor receptor protein where leucine has been replaced by lysine. 